\title{
Relevance of prolonged first mating in reproductive bioactivities of Dysdercus koenigii (FABRICIUS, 1775) (Heteroptera: Pyrrhocoridae)
}

\author{
KAMAL Kumar GuPTA*, MOHD SHAZAD, SHAILENDRA KUMAR \\ Department of Zoology, Deshbandhu College, University of Delhi, Kalkaji, \\ New Delhi, India
}

\begin{abstract}
Adults of Dysdercus koenigii remain in continuous copula for up to $72 \mathrm{~h}$. The adaptive significance of prolonged copulation in the reproductive bioactivities of $D$. koenigii was investigated by a series of interrupted mating experiments. The adults were allowed to mate for a specified duration, after which mating was forcibly terminated. The study indicated that insemination in the female takes place during the first day of mating. This was reflected by the observation that $24 \mathrm{~h}$ mated females laid fertile eggs. Prolonged mating modifies the female's reproductive behaviour. The duration of mating had a profound effect on the onset of oviposition as well as the total number of eggs and egg batches laid by a female during her lifetime. Female fertility was also correlated with the duration of mating. Therefore, a female mated for $24 \mathrm{~h}$ laid fewer fertile eggs in comparison to females mated for $48 \mathrm{~h}$ or $72 \mathrm{~h}$. Hatching success decreased significantly in the egg batches laid by a female during the latter part of her life. A mated female exhibited rhythmic ovipositional behaviour. Our results indicated that the rhythmicity of the oviposition changed as a consequence of the different duration of mating. For instance, in females mated for $24 \mathrm{~h}$, there was a change in the number of eggs laid and in the rhythmicity of ovipositional peaks. Further, the rate of oocyte growth appeared to be enhanced by mating. This was evidenced by the shorter inter-oviposition period in the case of females mated for a longer period. It is suggested that throughout mating, females acquire additional sperm and non-gametic resources, such as male accessory gland secretions, which govern their reproductive behaviour and physiology.
\end{abstract}

KEY WORDS: Dysdercus koenigii, Mating, Oviposition behaviour, Fecundity, Fertility.

* Corresponding author: kgupta@db.du.ac.in 


\section{INTRODUCTION}

One of the remarkable features of insects is their immense reproductive potential. The chances of reproductive success in insects to some extent are determined by their mating behaviour. Mating in insects involves a sequence of events which bring potential mates close together, and help in the recognition of species, sex and the potential mate. Mate finding, mate recognition and courtship behaviour, mating receptivity, mate selection, mating frequency and duration of copulation are important components of mating behaviour in insects, which adopt a specific set of these behavioural responses in order to maximize their reproductive output (THORNHILL \& ALCOCK 1983). The duration of mating is a highly variable component in this behaviour. In some insects, mating is completed within a short time; in many others, on the other hand, the mating pairs remain in continuous copula for several hours (ALCOCK 1994). The males of many insects exhibit post-insemination association, i.e. they prolong copulation well past the time required to transfer a sufficient number of gametes to fertilize all the female eggs. Prolonged copulation is one of the most important forms of post-insemination association, apart from monitoring the mate without physical contact (TSUBAKI \& ONO 1985), or donating a mating plug (EHRLICH \& EHRLICH 1978). Many insects remain in copula far beyond the time needed strictly for insemination (MCLAIN 1980, SiLlen-TUlBerg 1981, CARROLL \& LOYE 1990, CARROLL 1991). Prolonged mating may help in mate guarding, thus improving the male's chances of egg fertilization by keeping rivals away from their mate.

Dysdercus koenigii (FABRICIUS, 1775), commonly known as the red cotton bug, is a polyphagous pest of great economic importance. The pest causes considerable damage to standing crops of malvaceous plants, especially cotton (ATWAL 1976, CROWE 1977). Both the nymphs and the adults suck sap from the developing seeds, which thus lose their oil content and their germinating capacity. D. koenigii performs a complex set of physiological and behavioural feats in order to reproduce. Especially noteworthy in its reproductive behaviour is that a major part of its life passes in copula: an adult mates 5-7 times in its entire lifetime and each mating lasts 2-3 days (GuPTA \& SEHGAL 1995). The adults of $D$. koenigii become sexually mature $72 \mathrm{~h}$ after emergence and remain sexually receptive throughout their lifespan. The first mating is of the longest duration and usually lasts ca $72 \mathrm{~h}$, after which the female begins to oviposit. Between two successive matings there is bout of oviposition. Multiple matings enhance the reproductive success of $D$. koenigii. Unfortunately, no information is available pertaining to the significance of prolonged mating in D. koenigii: studies of mating behaviour would have favourable prospects in pest management. Manipulation of mating behaviour reduces this pest's reproductive potential, thereby reducing its population (CADRE \& MINKS 1995, FOSTER \& HARRIS 1997). This has led to targeted research into the significance of prolonged copulation. The present work 
investigated the influence of the duration of first mating on oviposition behaviour, fecundity and fertility.

\section{MATERIALS AND METHODS}

The present investigations were carried out on adults of the red cotton bug Dysdercus koenigii. A culture of $D$. koenigii was maintained at a temperature of $28 \pm 2^{\circ} \mathrm{C}, 70 \%$ relative humidity and a $12 \mathrm{~h}$ photoperiod regimen. The insects were provided with cotton seeds which had been washed thoroughly and dried on filter paper. A wet cotton swab was provided in each jar as a source of water for the insects. For experimental purposes, fifth instar nymphs were isolated and separated from the stock culture. Their sex was identified on the basis of relative size: female nymphs were broader and stouter than the male nymphs (KAYESTH \& GUPTA 2018). The male and the female nymphs were placed in separate jars. The newly emerged adults ( $0-4 \mathrm{~h}$ old), identified by the lesser amount of pigmentation and the absence of distinct markings on the fore wings, were separated and used in the experiment.

The insects were allowed to mate three days after emergence, when they were sexually mature and ready to mate. The males and the females remained in continuous copula for ca 3 days. The adaptive significance of prolonged copulation in reproductive success of $D$. koenigii was studied in three groups of 25 females each. In the first group the females were allowed to mate for $24 \mathrm{~h}$; the mating was subsequently terminated by separating the males and females with the aid of a fine camel-hair brush. In the second group the females were separated from copula after $48 \mathrm{~h}$. The females in the third group were allowed to mate for $72 \mathrm{~h}$, after which the first mating normally ends. The eggs laid by each female were counted daily and recorded. The experiments were conducted for 37 days, after which most of the experimental females died. The eggs were incubated in hatching vials and hatching success was evaluated. The data were analysed to determine and compare the preoviposition period, longevity, reproductive longevity, fecundity (total number of eggs laid in the lifespan) and fertility (percentage egg hatch) in the experimental females. The influence of the copulation period on oviposition behaviour was assessed by comparing various parameters such as the number of egg batches laid, the number of eggs in each batch, the time interval between two successive egg batches (inter-oviposition period) and the oviposition rhythms of each group of females which had mated for a specified duration. The results were statistically analysed using IBM SPSS 19.1software. One way Anova followed by 'Tukey post hoc test' was used to test the significant difference between groups. Results with $\mathrm{p}<0.05$ were considered to be statistically significant. 


\section{RESULTS}

Data on the influence of mating duration on the longevity and reproductive potential of female D. koenigii are presented in Fig. 1. The results showed that female longevity was not influenced by mating duration and that the difference in the average longevity of the three groups of females, i.e. mated for $24 \mathrm{~h}, 48 \mathrm{~h}$ and $72 \mathrm{~h}$ was statistically not significant (Fig. 1A). The reproductive longevity, i.e. the period when the females were actively reproducing, also remained largely unaffected by the duration of mating (Fig. 2).

However, the duration of mating did have a profound effect on the onset of oviposition in the females. If allowed to mate for $72 \mathrm{~h}$ or more, females tended to lay eggs soon after the termination of mating. The average preoviposition period was 6.4 days. However, in the females mated for $24 \mathrm{~h}$ the preoviposition period increased to 12.3 days, whereas in the females mated for $48 \mathrm{~h}$ this period was 7.8 days (Fig. 1B).

The fecundity of females of $D$. koenigii was correlated with their duration of mating as manifested by the total number of eggs and egg batches laid by them in their entire lifespan (Fig. 1C). A female mated for $72 \mathrm{~h}$ laid an average of 293.1 eggs. However, the average number of eggs laid fell to 245 in $48 \mathrm{~h}$ mated females and to 184.3 in $24 \mathrm{~h}$ mated females. Prolonged mating also influenced female fertility (Fig. 1D). The hatching success of the eggs laid by the females mated for $24 \mathrm{~h}$ was $67.19 \%$. This indicated that sperm transfer took place during the first day of mating. Females mated for $72 \mathrm{~h}$ laid more fertile eggs (hatching success $81.32 \%$ ) than the those mated for $48 \mathrm{~h}$ (hatching success $72.41 \%$ ).

Data on the daily oviposition pattern of females mated for $24 \mathrm{~h}, 48 \mathrm{~h}$ and $72 \mathrm{~h}$ are presented in Fig. 2. The results indicate that the oviposition pattern of the females showed a distinct rhythmic pattern: high oviposition peaks were followed by low oviposition peaks. The oviposition peaks were separated by a distinct time interval. In the $72 \mathrm{~h}$ mated females, oviposition started early in life: $64 \%$ of such females were reported ovipositing on the sixth day of their life. The rate of oviposition during subsequent days was also quite high. The high oviposition peaks in these females were separated by short time intervals during the first nine days. Subsequently, the periodicity of high oviposition was repeated but after a longer time span. The high egg output in the females mated for $72 \mathrm{~h}$ was related to the number of ovipositing females on a specific day (Fig. 2). The magnitude of a high ovipositional peak was smaller in $24 \mathrm{~h}$ mated females; also, the high ovipositional peaks were separated by a longer time interval. Females oviposited less during the latter part of their life, i.e. 9 days after emergence just a few females were observed ovipositing. Females mated for $48 \mathrm{~h}$ resembled the $72 \mathrm{~h}$ mated females in their oviposition rhythms, but the $48 \mathrm{~h}$ mated females exhibited fewer high ovipositional peaks and a low magnitude of these peaks in the latter part of their life. Mating duration was responsible for maintaining regular and 

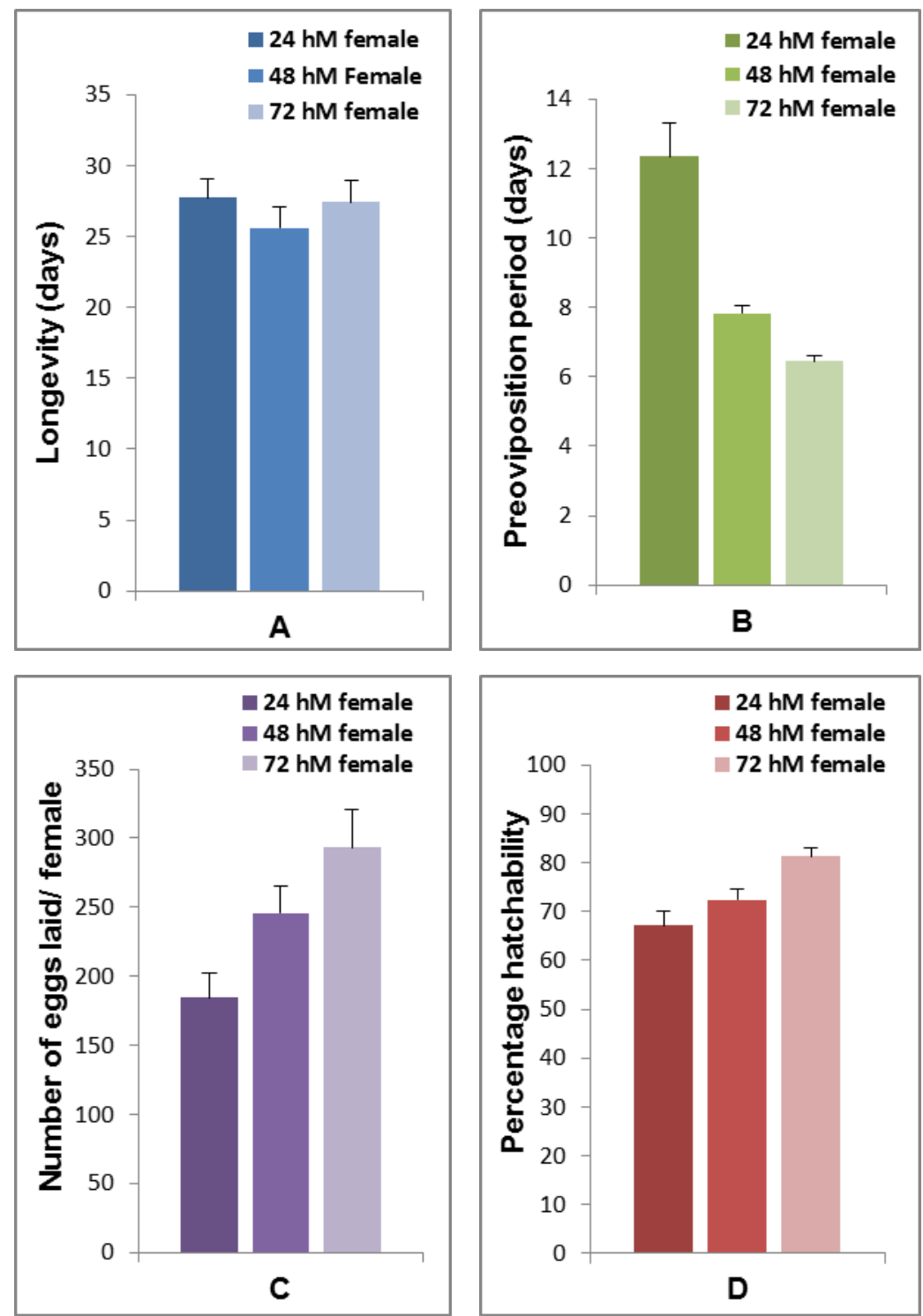

Fig. 1. Longevity and reproductive behaviour of singly mated females of Dysdercus koenigii as influenced by the duration of mating. A - Longevity; B - Preoviposition period; $\mathrm{C}$ - Number of eggs laid per female; D - Percentage hatchability; $24 \mathrm{hM}-24 \mathrm{~h}$ mated females; $48 \mathrm{hM}$ - $48 \mathrm{~h}$ mated females; $72 \mathrm{hM}-72 \mathrm{~h}$ mated females. 


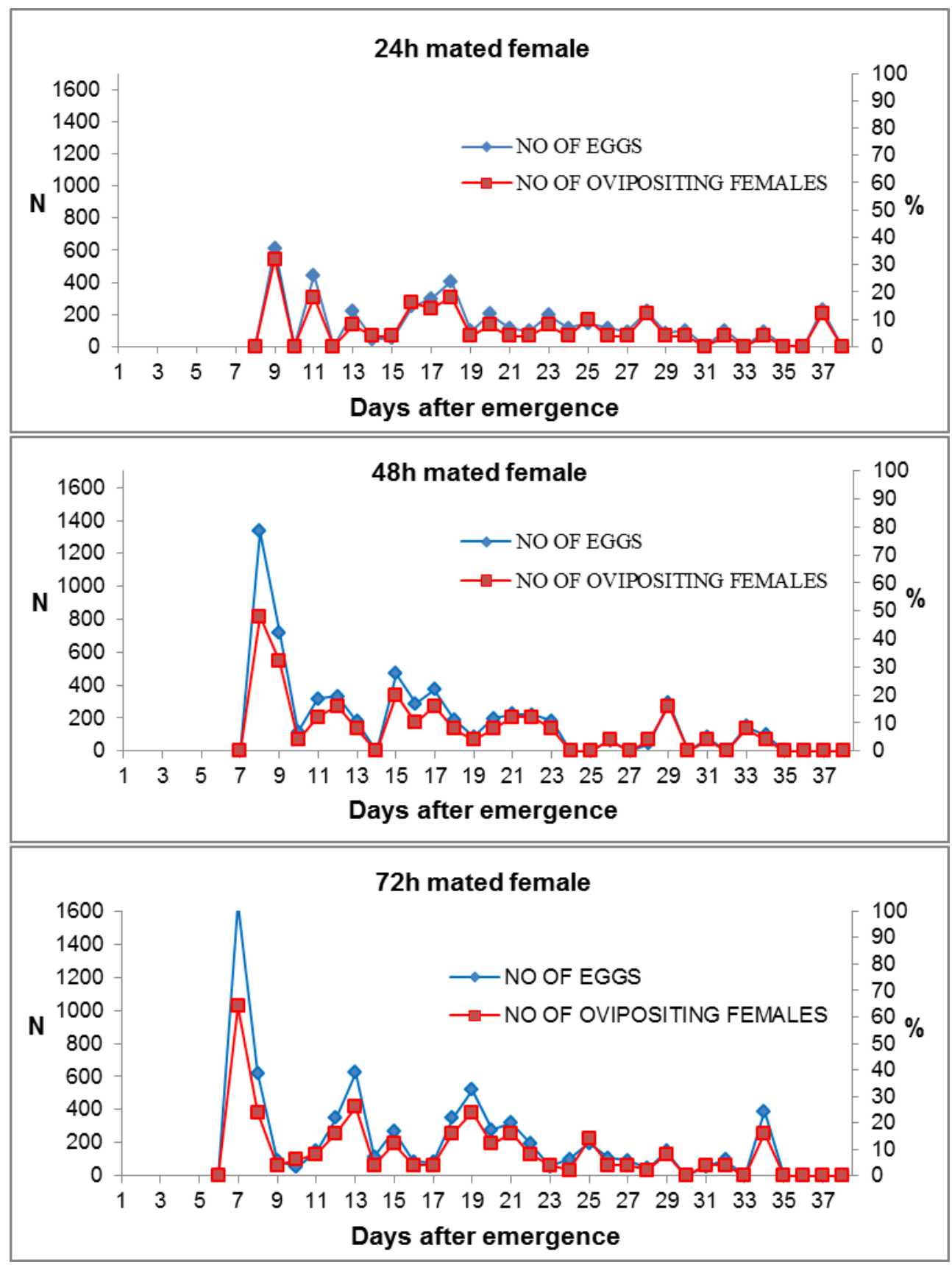

Fig. 2. Daily oviposition pattern of singly mated females of Dysdercus koenigii as influenced by the duration of the first mating. $\mathrm{N}-$ number of eggs laid per day, $\%-\%$ of ovipositing females. 


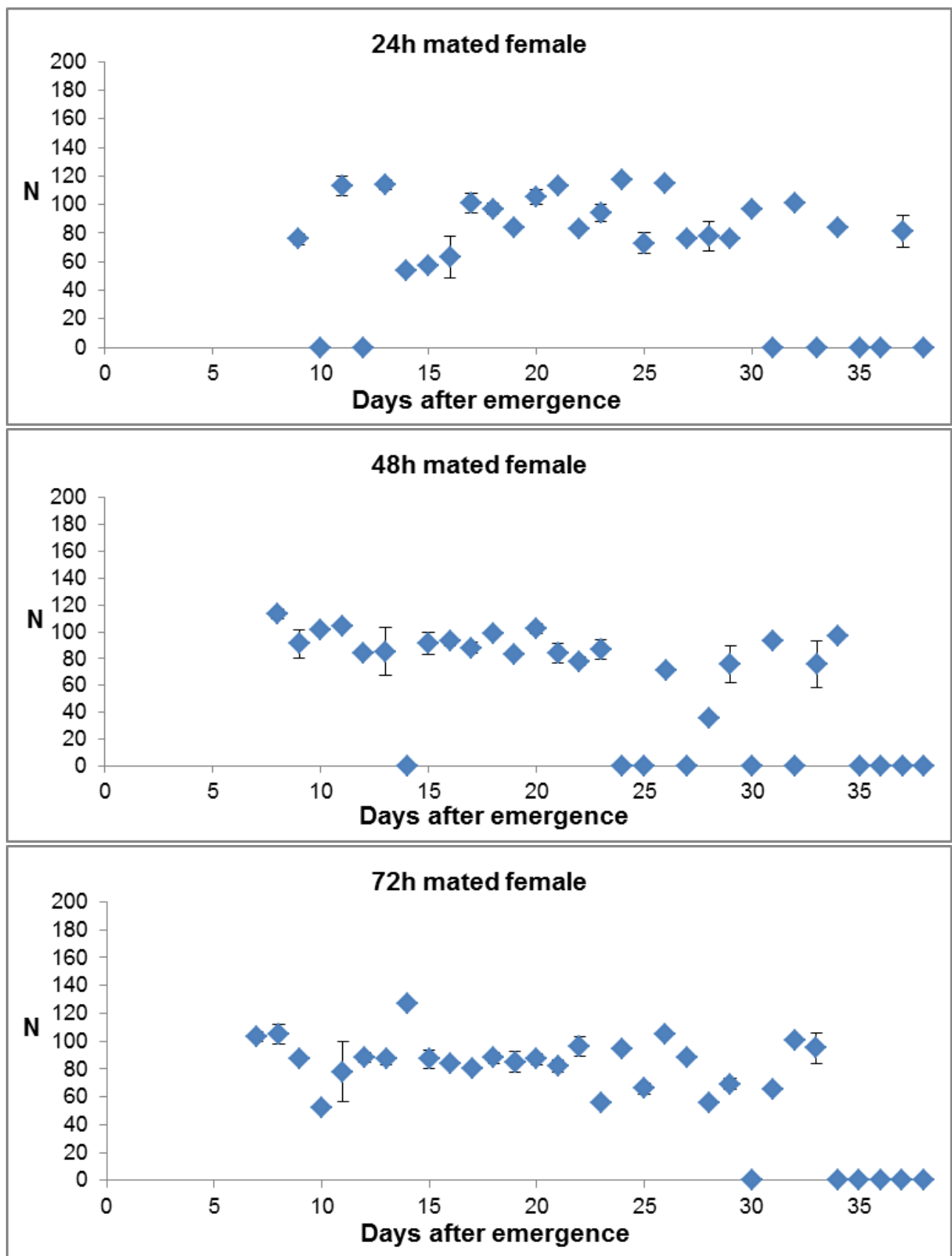

Fig. 3. Average egg production of singly mated females of Dysdercus koenigii. Egg output $(\mathrm{Mean} \pm \mathrm{S}$.E)/day/female as influenced by the duration of mating. None of the females oviposited everyday. $\mathrm{N}$ - number of eggs laid. 


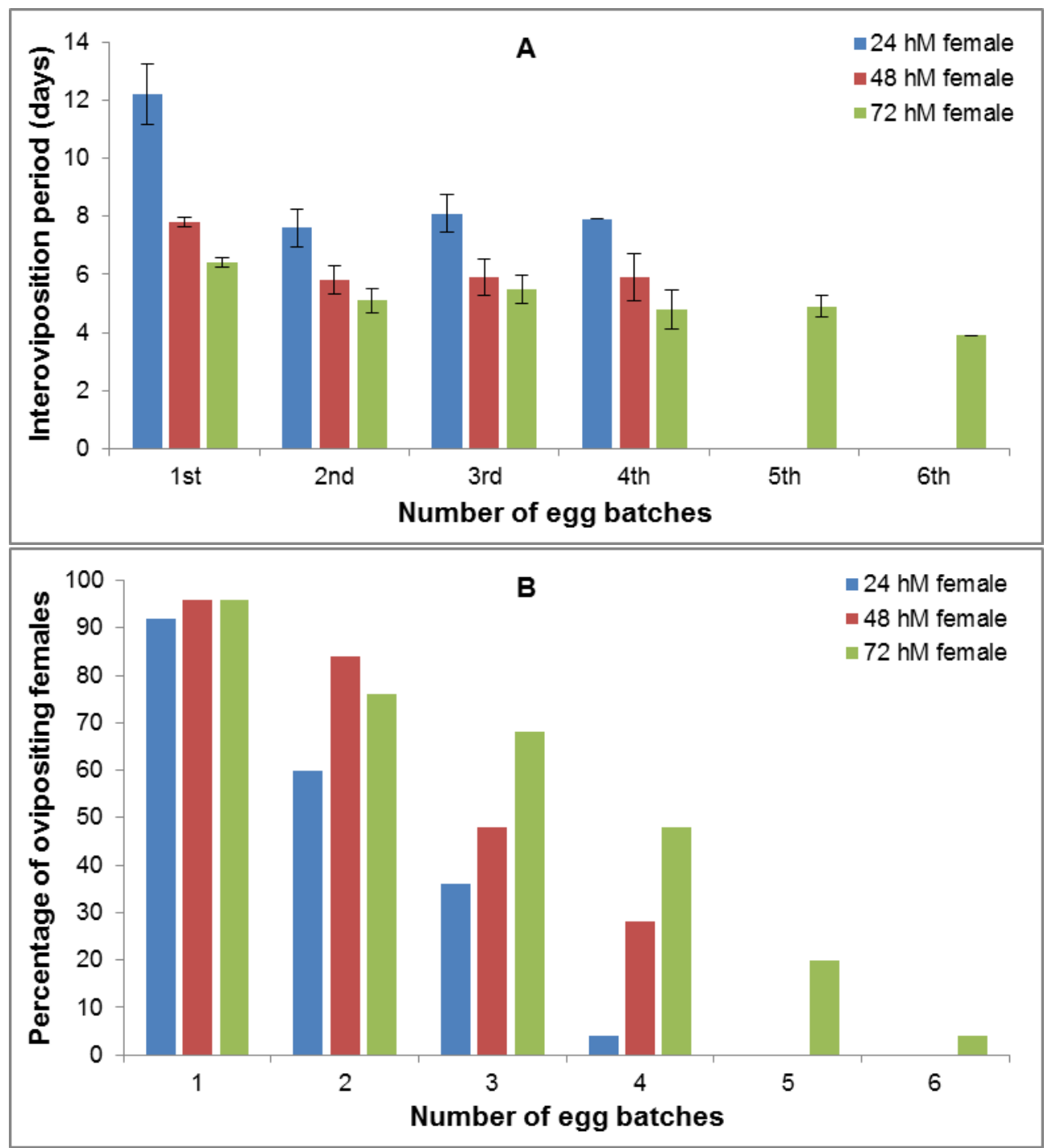

Fig. 4. Oviposition behaviour of singly mated females of Dysdercus koenigii in relation to their duration of mating. A - Inter-oviposition period between two successive egg batches and the female response; B - Number of egg batches laid and the female response; $24 \mathrm{hM}$ $24 \mathrm{~h}$ mated females; $48 \mathrm{hM}-48 \mathrm{~h}$ mated females; $72 \mathrm{hM}-72 \mathrm{~h}$ mated females.

uniform oviposition behaviour (Fig. 3). The number of eggs laid by $72 \mathrm{~h}$ mated females was more or less uniform for most of their reproductive life. Therefore, the number of eggs laid/day/female varied from 78 to 127 during the first 22 days of their life cycle, except on 
day 10 , when the number of eggs laid /day/female was 52 . On the other hand, a female mated for $24 \mathrm{~h}$ displayed more irregular oviposition behaviour, as reflected by the range of the number of eggs laid/day/female. The number of eggs laid/day/female during the entire lifespan was highly variable, from 54 to 117.

In order to ascertain the influence of mating duration on the lifetime reproductive programming of females, parameters like the inter-oviposition period, the number of eggs laid in each batch and the hatching success of each batch were assessed. The data in Fig. 4B reveal a striking difference in the number of egg batches laid by females of different mating status. The $72 \mathrm{~h}$ mated females laid up to six batches, whereas females mated for $24 \mathrm{~h}$ and $48 \mathrm{~h}$ laid a maximum four. It was also observed that $48 \%$ of the $72 \mathrm{~h}$ mated females laid four egg batches, whereas only $28 \%$ of $48 \mathrm{~h}$ mated females and only $4 \%$ of $24 \mathrm{~h}$ mated females laid the same number of batches (Fig. 4B). The results also showed that there was a striking difference in the inter-oviposition period in the three groups of females (Fig. 4A). The rate of oocyte development appeared to be faster in the females mated for $72 \mathrm{~h}$. These females, therefore, laid their first egg batch after an average period of 6.4 days, and usually laid subsequent batches after an interval of 5-6 days. In contrast, the first egg batch in the $24 \mathrm{~h}$ mated females was delayed for up to 12 days, with subsequent egg batches being laid after intervals of 7-8 days. In the $48 \mathrm{~h}$ mated females the first egg batch was delayed for about 8 days, but thereafter subsequent batches were laid after intervals of 5-6 days.

As stated earlier, the $72 \mathrm{~h}$ mated females laid more eggs than $24 \mathrm{~h}$ or $48 \mathrm{~h}$ mated females; this was on account of the larger number of batches laid by the females of different mating status in their lifespan. However, the differences between the numbers of eggs in the batches laid by the females in the different mating groups were not statistically significant (Table 1). The hatching success of the eggs laid by the three groups of females mated for $24 \mathrm{~h}, 48 \mathrm{~h}$ and $72 \mathrm{~h}$ was $92.8 \%, 81.5 \%$ and $74.8 \%$ respectively. The results also indicated that there was a gradual decrease in the hatching success of the egg batches laid in all three groups of females, especially during the latter part of life. In the $72 \mathrm{~h}$ mated females the hatching success of the first egg batch was $92.8 \%$, decreasing to $61 \%$ in the fourth batch laid. The lower hatching success of the batches laid in later life was more pronounced in the $24 \mathrm{~h}$ and $48 \mathrm{~h}$ mated females. This parameter dropped from $81 \%$ in the first egg batch to $47 \%$ in the last batch in the $48 \mathrm{~h}$ mated females, whereas in the $24 \mathrm{~h}$ mated females, hatching success declined from $74 \%$ in the first batch to $47 \%$ in the last one (Table 1). The results therefore indicated that the duration of mating did affect the fertility of the egg batches laid by females in the latter part of their lives. 


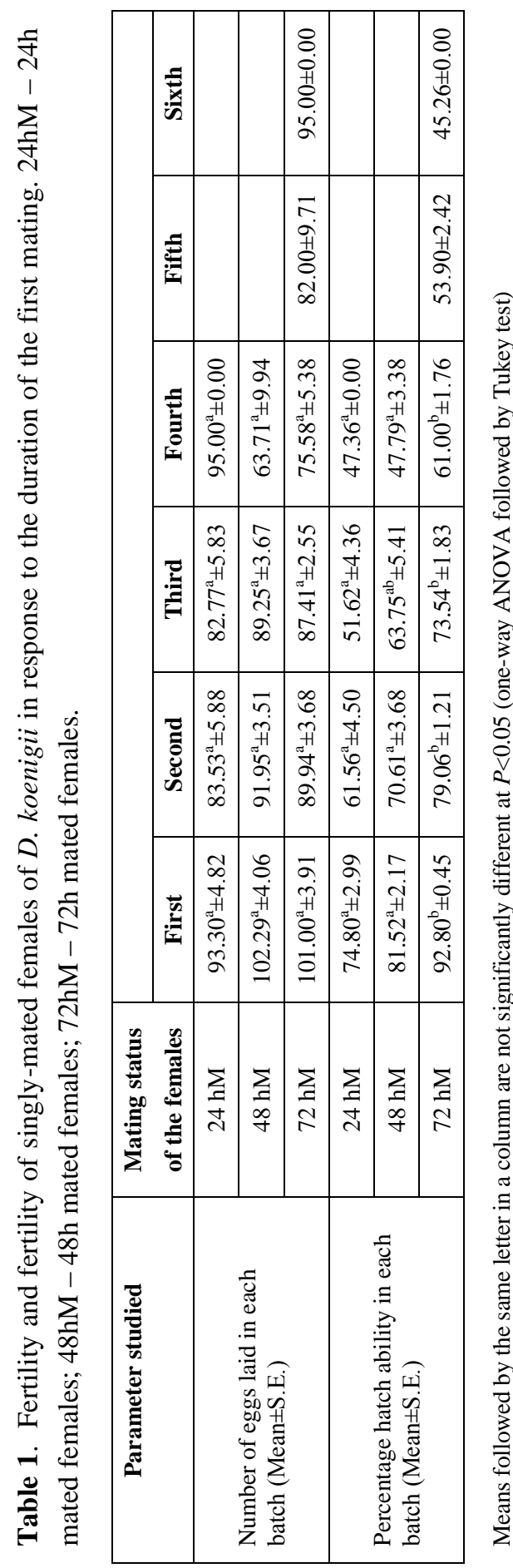

\section{DISCUSSION}

Many insects remain in copula far beyond the time strictly needed for insemination (MCLAIN 1980, SILLENTUlberg 1981, CARROLL \& LOYE 1990, CARROLL 1991). Our studies on mating behaviour in $D$. koenigii indicate that mating pairs remain in continuous copula for up to $72 \mathrm{~h}$. This is similar to Jadera haematroloma (HERRICH-SCHÄFFER, 1847) (CARROLL 1991): in this rhopalid bug, mating can last up to 11 days. Postinsemination association between the sexes involving prolonged copulation have been reported in many heteropteran insects (MCLAIN 1980, SILLEN-TULBERG 1981, CARROLl \& LOYE 1990, CARROLL 1991). This suggests that prolonged mating confers selective advantages on both males and females. Prolonged mating may benefit males by enabling them to reduce their efforts to repel other sexually motivated males (WALKER 1980). Copulation may be prolonged to permit the male to remove or manipulate the previously received ejaculate of another male (WAAGE 1986). Further, prolonged mating may be used for additional courtship signals that cause a female to use the male's sperm to fertilize her eggs (EBERHARD 1988). Prevention of a female from prematurely consuming or removing the spermatophore is also a function attributed to prolonged mating (SAKALUK 1991). Prolonged mating in D. koenigii appears to be associated with 
the optimization of the male's reproductive efforts. Our earlier studies indicated some unique features in the mating behaviour of this insect, i.e. a strong motivation on the part of the males to mate; brief courtship behaviour; lack of conspicuous mate selection behaviour in the females; continued mating receptivity of the female (GUPTA 1990, GUPTA \& SEHGAL 1997). These factors may have generated a need for mate guarding behaviour in male $D$. koenigii. During the course of evolution, D. koenigii adopted a strategy to remain in continuous copula until the female begins ovipositing. This ensures that the female utilizes his sperm to fertilize her eggs and hence represent his genotype in the future progeny. The males of many species respond in this way to avoid post-mating competition (PARKER et al. 1996, PARKER et al. 1997, WEDELL et al. 2002, WiGBY et al. 2009, BRETMAN et al. 2011). Our results agree with the study on various species of Drosophila FALLÉN, 1823, where males, if exposed to rivals prior to mating, mate for a significantly longer time than the control (BRETMAn et al. 2009, MAZZI et al. 2009, LizÉ et al. 2012, PRICE et al. 2012).

Prolonged mating may confer multiple adaptive functions and offer the two sexes different fitness benefits. Such an association may benefit the mates by providing additional sperm (YASUI 1997), or non-gametic male-specific material resources (CHEN 1984, RAABE 1986, GUPTA \& SEHGAL 1995). Male accessory secretions improve the female's nutritional status (GWYNNE 1986, BISSOONDTH \& WILKUND 1996, WEDELL et al. 2002) and increase her fecundity (GUPTA 1990). Additional advantages of prolonged mating in the lifetime reproductive success of female $D$. koenigii were studied by forcibly separating the mating pairs in order to terminate mating. The females were thus allowed to mate for just a fixed period of time. Our results indicated that the females of various mating status exhibited differences in oviposition behaviour, fecundity and fertility. The females mated for $72 \mathrm{~h}$ laid the first batch of eggs as soon as the first mating was over, whereas oviposition was delayed in the females mated for a shorter time. Therefore, it was surmised that prolonged mating accelerates the rate of oocyte development in the females. In Bombyx mori (LINNAEUS, 1758), Punitham et al. (1987) reported that an increase in mating duration of up to $6 \mathrm{~h}$ reduced the preoviposition period, increased total egg output and increased fertility. Similarly, the reproductive performance of Ostrinia nubilalis (HÜBNER, 1796) was affected by the duration of mating (FADAMIRO \& BAKER 1999). Prolonged mating also affected the total egg output in Dysdercus koenigii. Hence a $72 \mathrm{~h}$ mated female laid more eggs and batches than females mated for a shorter period. In Drosophila it has been reported that the proteins contained in the seminal fluid are transferred during mating: this causes mated females to accelerate the egg-laying rate (TRAM \& WOLFNER 1999). HARRIS \&TODD (1980) reported that in Nezara viridula (LINNAEUS, 1758) there is direct correlation between the duration of mating and egg production by the female. It is possible that some non-gametic component of the male ejaculate enhances fecundity in Dysdercus koenigii. The male accessory secretions have been shown to be transferred throughout copulation (GUPTA 
1990), and role of male accessory secretions in enhancing fecundity in insects has been well documented (CHEN 1984, RAABE 1986). Further, it has been shown that the male seminal ejaculate contains various nutrients that are transferred to the female at the time of mating. This enables the female to lay a larger number of eggs of increased viability (GWYNNE 1986, 1988). PARK et al. (1998) described the role of the male factor in governing egg maturation and oviposition in Heliothis virescens (FABRICIUS, 1777). Our studies indicate that females can lay fertile eggs after $24 \mathrm{~h}$ of mating. This suggests that insemination and sperm transfer in Dysdercus koenigii takes place during the first $24 \mathrm{~h}$ of mating. However, the percentage hatching success was related to the duration of mating. A female, if mated for $72 \mathrm{~h}$, laid more fertile eggs than a female mated for $24 \mathrm{~h}$ or $48 \mathrm{~h}$. This was in agreement with reports of increased fertility in many beetles as a consequence of prolonged mating (CORDERO 1990).

The duration of mating had a profound effect on the oviposition behaviour of the females. $72 \mathrm{~h}$ mated females exhibited an ordered oviposition behaviour with regular rhythms of discrete peaks of high egg output separated by low egg output for the majority of her lifespan. On the other hand, 24h mated females deviated from such rhythmic oviposition behaviour, and $48 \mathrm{~h}$ mated females differed with the $72 \mathrm{~h}$ females in their oviposition pattern during the latter part of their lives. The range of eggs laid/day/female was narrow in the females mated for $72 \mathrm{~h}$, but more variable in $24 \mathrm{~h}$ and $48 \mathrm{~h}$ mated females. The role of mating duration in oviposition rhythms was documented in Atherigona soccata (RONDANI, 1871) (OGWARO 1978) and crickets (SIMMONS 1988). The difference in the total number of eggs laid in the three groups of females was related to the number of egg batches laid and not to the number of eggs laid in one batch. All three groups of females laid fertile eggs, indicating transfer of spermatozoa early during mating. In Bombus terrestris (LINNAEUS, 1758) males transfer enough sperm into the female genital tract during the first 2 min of mating (DuvoIsIN et al. 1999, AMIN et al. 2009). It has also been reported that the fertility of egg batches laid in later life is greatly reduced in the females mated for $24 \mathrm{~h}$ or 48h. As suggested by YASUI (1997), additional sperms are transferred to the female during the entire course of mating. Thus, the non-gametic resources of the males and the sperm transferred during prolonged copulation enhance the female's fecundity and fertility. The non-gametic specific material resources of males have been documented as influencing female reproductive physiology (CHEN 1984, RAABE 1986), improving her nutritional status (WEDELL et al. 2002) and increasing her fecundity (GUPTA 1990).

\section{REFERENCES}

ALCOCK J. 1994. Postinsemination association between males and females in insects: The mateguarding hypothesis. Annual Review of Entomology, 39 (1): 1-21. 
Amin M.R., Than K.K., Kwon Y.J. 2009. Copulation duration of bumblebee Bombus terrestris (Hymenoptera: Apidae): Impacts on polyandry and colony parameters. Journal of Asia-Pacific Entomology, 12 (3): 141-144.

Atwal A.S. 1976. Agricultural pests of India and South East Asia. Kalyani Publishers, New Delhi.

Bissoondth C.J., WiLKUND C. 1996. Male butterfly investment in successive ejaculates in relation to mating system. Behavioural Ecology and Sociobiology, 39 (5): 285-292.

BretMan A., Fricke C., ChAPMAN T. 2009. Plastic responses of male Drosophila melanogaster to the level of sperm competition increase male reproductive fitness. Proceedings of the Royal Society of London B: Biological Sciences, 276 (1662): 1705-1711.

Bretman A., Gage M.J.G., Chapman T. 2011. Quick-change artists: adult behavioural plasticity at mating. Trends in Ecology and Evolution, 26 (9): 467-473.

CAdRe R.T., Minks A.K. 1995. Control of moth pests by mating disruption: Successes and constraints. Annual Review Entomology, 40 (1): 559-585.

CARROLL S.P. 1991. The adaptive significance of mate guarding in the soapberry bug Jadera hematoloma (Hemiptera: Rhopalidae). Journal of Insect Behavior, 4 (4): 509-530.

CARROll S.P., LOYE J.E. 1990. Male biased sex ratio female promiscuity and copulatory mate guarding in an aggregating tropical bug, Dysdercus bimaculatus. Journal of Insect Behavior, 3 (1): $33-48$.

CHEN P.S. 1984. The functional morphology and biochemistry of insect male accessory glands and their secretions. Annual Review of Entomology, 29: 233-255.

CORDERO A. 1990. The adaptive significance of prolonged copulation of the damselfly, Ischnura graellsii (Odonata: Coenagrionidae). Animal Behaviour, 40 (1): 43-48.

Crowe T.J. 1977. Pyrrhocoridae: Dysdercus spp. [in:] J. Kranz, H. Schmutterer, W. Kosch (eds.). Diseases, pests and weeds in tropical crops. Verlag Paul Parey, Berlin, 298-300.

Duvoisin N., Baer B., Schmid-Hempel P. 1999. Sperm transfer and male competition in a bumblebee. Animal Behaviour, 58 (4): 743-749.

EBERHARD W.G. 1988. Paradoxical post-copulating courtship in Minantigera nigrifemorate (Diptera: Stratiomyidae). Psyche, 95: 115-122.

EHRLICH A.H., EhrLICH P.R. 1978. Reproductive strategies in the butterflies: 1. Mating frequency, plugging and egg number. Journal of Kansas Entomological Society, 51 (4): 666-697.

FADAMIROH.Y., BAKER T.C. 1999. Reproductive performance and longevity of female European corn borer, Ostrinia nubilalis: effects of multiple mating, delay in mating, and adult feeding. Journal of Insect Physiology, 45 (4): 385-392.

FoSTER S.P., HARRIS M.O. 1997. Behavioural manipulation method for insect pest management. Annual Review of Entomology, 42 (1): 123-146.

GUPTA K.K. 1990. Accessory reproductive glands of Dysdercus koenigii FABRICIUS: Developmental anatomy, physiology and role of their secretions in female reproduction. Ph.D. thesis, University of Delhi, New Delhi.

GuPTa K.K., SEHGal S.S. 1995. Influence of multiple mating on reproductive success of Dysdercus koenigii FABRICIUS. Shashpa, 2: 33-41. 
GuPTA K.K., SehgaL S.S. 1997. Mechanism of mate finding and recognition in mating behaviour of Red cotton bug. Bulletin of Entomology, 38 (1/2): 18-22.

GwYNNE D.T. 1986. Courtship feeding in katydids (Orthoptera: Tettigoniidae): investment in offspring or in obtaining fertilizations? The American Naturalist, 128 (3): 342-352.

GwYNNE D.T. 1988. Courtship feeding and the fitness of female katydids (Orthoptera: Tettigonidae). Evolution, 42 (3): 545-555.

HARRIS V.E., TODD J.W. 1980. Temporal and numerical patterns of reproductive behaviour in the Southern green stink bug, Nezara viridula (Hemiptera: Pentatomidae). Entomologia Experimentalis et Applicata, 27 (2): 105-116.

KAYESTH S., GUPTA, K.K. 2018. Impact of Lantana camara hexane extract on survival, growth and development of Dysdercus koenigii FABRICIUS (Heteroptera: Pyrrhocoridae). Acta Ecologica Sinica, 38 (3): 187-192.

Lizé A., Doff R.J., Smaller E.A., Lewis Z., Hurst G.D.D. 2012. Perception of male-male competition influences Drosophila copulation behaviour even in species where females rarely remate. Biology Letters, 8 (1): 35-38.

Mazzi D., Kesäniemi J., Hoikkala A., Klappert K. 2009. Sexual conflict over the duration of copulation in Drosophila montana: why is longer better? BMC Evolutionary Biology, 9 (1): 132.

MCLAIN D.K. 1980. Female choice and the adaptive significance of prolonged copulation in Nezara viridula. (Hemiptera: Pentatomidae). Psyche, 87 (3-4): 325-326.

OGWARO K. 1978. Observations on longevity and fecundity of the sorghum shoot fly Atherigona soccata (Diptera: Anthomyiidae). Entomologia Experimentalis et Applicata, 23 (2): 131-138.

PARK V.I., RAMASWAMY S.B., SRINIVASAN A. 1998. Spermatophore formation and regulation of egg maturation and oviposition in female Heliothis virescens by the male. Journal of Insect Physiology, 44 (10): 903-908.

Parker G.A., Ball M.A., Stockley P., Gage M.J.G. 1996. Sperm competition games: individual assessment of sperm competition intensity by group spawners. Proceedings of the Royal Society of London B: Biological Sciences, 263 (1375): 1291-1297.

Parker G.A., Ball M.A., Stockley P., Gage M.J.G. 1997. Sperm competition games: a prospective analysis of risk assessment. Proceedings of the Royal Society of London B: Biological Sciences, 264 (1389): 1793-1802.

Price T.A., Lizé A., Marcello M., BretMan A. 2012. Experience of mating rivals causes males to modulate sperm transfer in the fly Drosophila pseudoobscura. Journal of Insect Physiology, 58 (12): $1669-1675$.

Punitham M.T., Haniffa M.A., ARunachalam S. 1987. Effect of mating duration on fecundity and longevity of eggs in Bombyx mori L. (Lepidoptera: Bombycidae). Entomon, 12 (1): 55-58.

RAABE M. 1986. Insect reproduction: Regulation of successive steps. Advances in Insect Physiology, 19: $29-154$.

SAKALUK S.K. 1991. Post-copulatory mate guarding in decorated crickets. Animal Behavior, 41 (2): 207-216. 
Sillen-Tulberg B. 1981. Prolonged copulation: a male 'postcopulatory' strategy in promiscuous species, Lygaeus equestris (Heteroptera: Lygaeidae). Behavioural Ecology and Sociobiology, 9 (4): $283-289$.

SIMMONS L.W. 1988. The contribution of multiple mating and spermatophore consumption to the lifetime reproductive success of female field crickets (Gryllus bimaculatus). Ecological Entomology, 13 (1): 57-69.

Thornhill R., Alcock J. 1983. The Evolution of Insect Mating Systems. Harvard University Press, Cambridge, MA.

TRAm U., Wolfner M.F. 1999. Male seminal fluid proteins are essential for sperm storage in Drosophila melanogaster. Genetics, 153 (2): 837-844.

TsUBAKI Y., ONO T. 1985. The adaptive significance of non-contact mate guarding by males of the dragonfly Nannophya pygmaea RAmBUR (Odonata: Libellulidae). Journal of Ethology, 3 (2): $135-141$.

WAAGE J.K. 1986. Sperm displacement by two libellulid dragonflies with disparate copulation durations (Anisoptera). Odonatologica, 15 (4): 429-444.

WAGNER W.E. 2011. Direct benefits and the evolution of female mating preferences: conceptual problems, potential solutions, and a field cricket. Advances in the Study of Behavior, 43: 273-319.

WALKER W.F. 1980. Sperm utilization strategies in non-social insects. The American Naturalist, 115 (6): 780-789.

Wedell N., Gage M.J., Parker G.A. 2002. Sperm competition, male prudence and sperm limited females. Trends in Ecology and Evolution, 17 (7): 313-320.

Wigby S., Sirot L.K., Linklater J.R., Buehner N., Calboli F.C.F., Bretman A., Wolfner M.F., Chapman T. 2009. Drosophila melanogaster males modify seminal fluid protein transfer in response to social cues and artificial selection on accessory gland size. Current Biology, 19: $751-757$.

YASUI Y. 1997. A 'good sperm' model can explain the evolution of costly multiple mating by females. The American Naturalist, 149 (3): 573-584.

Received: 12 June 2018

Accepted: 18 October 2018 